\title{
Synthesis, Structure and Electric Transport Properties of $\mathrm{Sr}_{3} \mathrm{NbCrO}_{7}$
}

\author{
Veer Singh ${ }^{1}$, Jaya Dwivedi ${ }^{2} \&$ Indu Bhushan Sharma ${ }^{1}$ \\ ${ }^{1}$ ISCAS Institute of Solid State and Materials Science, Jammu University Campus, Jammu, India \\ ${ }^{2}$ Department of Chemistry, Banasthali University, Banasthali, India \\ Correspondence: Indu Bhushan Sharma, ISCAS Institute of Solid State and Materials Science, Jammu \\ University Campus, Jammu 180006, India. E-mail: indubsharma@rediffmail.com
}

Received: November 5, 2012 Accepted: November 23, 2012 Online Published: December 24, 2012

doi:10.5539/jmsr.v2n1p148 URL: http://dx.doi.org/10.5539/jmsr.v2n1p148

\begin{abstract}
A new phase with the composition $\mathrm{Sr}_{3} \mathrm{NbCrO}_{7}$ has been synthesised by the standard ceramic method. X-ray diffraction studies show that the phase crystallises in the RP-type $(n=2)$ structure with tetragonal unit cell $(\underline{a}=$ 3.994 and $\underline{\mathrm{c}}=21.015 \AA$ ) in the space group $\mathrm{I} 4 / \mathrm{mmm}$. The electrical resistivity measurements as a function of temperature suggest that the phase is semiconductor in nature in the temperature range 100-300 $\mathrm{K}$ and the conduction occurs by $3 \mathrm{D}$ hopping mechanism.
\end{abstract}

Keywords: $\mathrm{Sr}_{3} \mathrm{NbCrO}_{7}$, RP-type, XRD studies, electrical resistivity, hopping conduction

\section{Introduction}

The Ruddlesden-Popper-type phases have been subject matter of intense studies for their wide range of properties. These phases are represented by the composition $\mathrm{A}_{n+1} \mathrm{~B}_{n} \mathrm{O}_{3 n+1}$, where usually B-site is occupied by one or more transition metal ion(s). It has been observed that these compounds, generally, crystallise in the space group I4/mmm or Fmmm with tetragonal or orthorhombic unit cell (Battle, 2004; Shilova, 2002; Shivakumar, 2004). RP-phases exhibit electic transport properties ranging from insulator to superconductivity behaviour. The nature and the valance state of the ion/ions at the position B and oxygen content immensely influence the transport properties (Mahesh, 1996; Sharma, 1999). It has been observed that some phases with the ions like $\mathrm{Mn}^{3+}$ exhibit colossal magnetoresistance due to induction of mixed valance state in these ions, where I-M transition accompanied by ferromagnetism is obsereved (Gupta, 2011; Helmolt, 1993; Ramirez, 1997; Tsipis, 2007). The presence of an ion with $e_{g}$ electron at the site $B$ leads to distortion of the unit cell, also known as John-Teller effect. This phenomenon results in interesting electric transport and magnetic properties (Matsukova, 2005).

In the present paper, synthesis of a new RP-type phase with the composition $\mathrm{Sr}_{3} \mathrm{NbCrO}_{7}$ has been reported. Its crystal structure has been determined from the powder X-ray diffraction data. Electric transport property has been studied in the temperature range $10-300 \mathrm{~K}$.

\section{Experimental}

\subsection{Synthesis}

Aldrich make $\mathrm{SrO}, \mathrm{Nb}_{2} \mathrm{O}_{5}$, and $\mathrm{Cr}_{2} \mathrm{O}_{3}$ (purity 99.9\%) have been used for synthesis of the new phase. The constitutent oxides, weighed corresponding to the stoichiometry $\mathrm{Sr}_{3} \mathrm{NbCrO}_{7}$, were pulverized and mixed by grinding in cyclohexane. The dried and homogenised mixture, pressed in to pellets in a hydraulic press, was heat-treated at $1348 \mathrm{~K}$ (with 10 degree variation) for 72 hours in the static air atmosphere. The mixture during heat-treatment was subjected to a number of intermediate grindings and pelletization for completion of the reaction. The product was pulverized for further studies.

\subsection{X-ray Diffraction Studies}

The powder X-ray diffraction data of the product were recored on a Rigaku Multiflux X-ray diffractometer in the $2 \theta$ range of $10-70^{\circ}$ at the scanning speed of $1 \%$ min. The X-ray diffraction pattern, intensity versus $2 \theta$, is drawn in the Figure 1, while the data are given in the Table 1. 


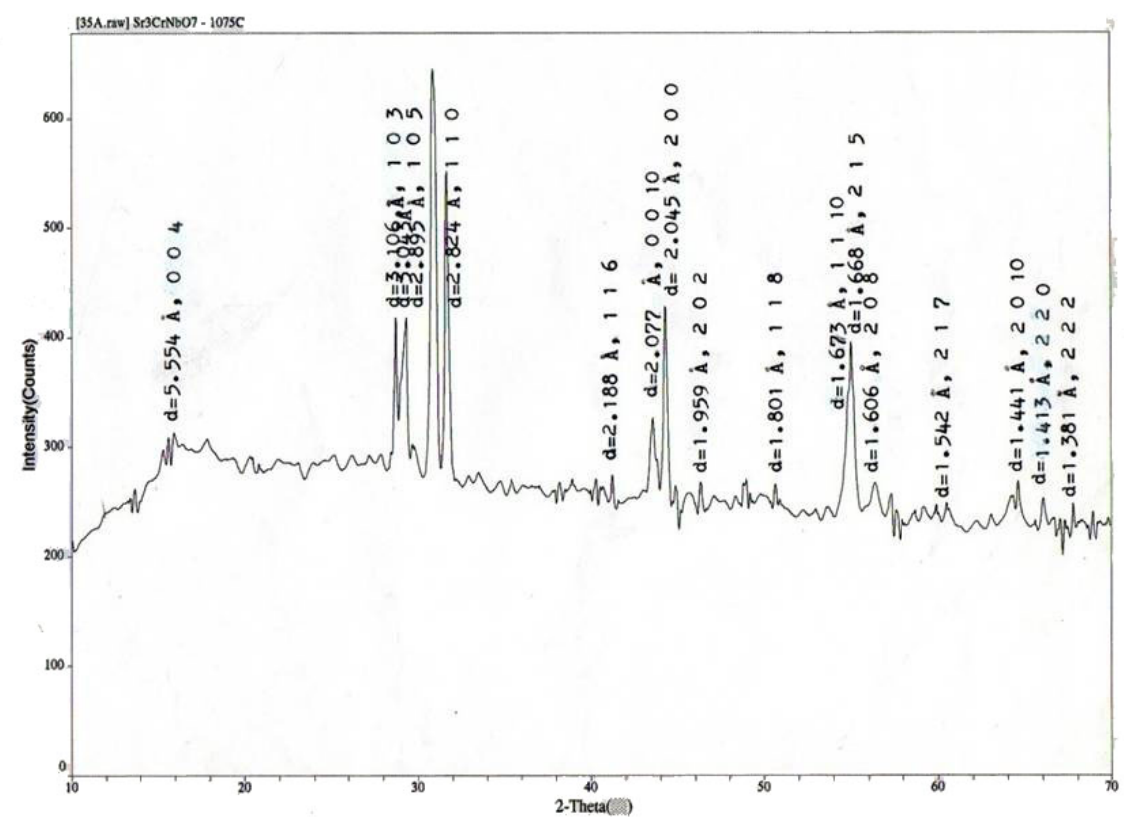

Figure 1. X-ray diffraction pattern of $\mathrm{Sr}_{3} \mathrm{NbCrO}_{7}$

\subsection{Electrical Resistance Study}

The electrical resistivity of thin pellet of the phase, sintered at $1200 \mathrm{~K}$ before use, was recorded in a Leybold closed cycle helium cryostat, using Keithley 6517 electrometer/high resistance meter. Thin copper wires were attached to the pellet using silver epoxy for the purpose of electrodes. The $\log \rho$ versus temperature (K) data are plotted in the Figure 2.

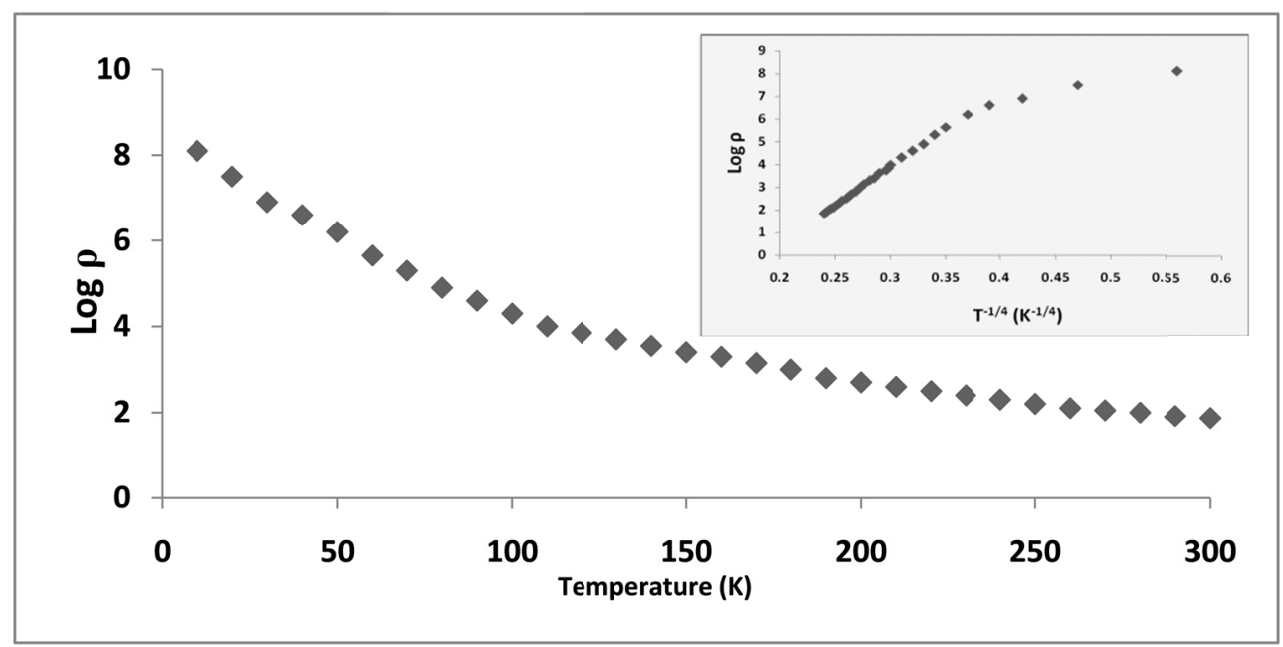

Figure 2. $\log \rho$ versus Temperature (K), (inset) $\log \rho$ versus $\mathrm{T}^{-1 / 4}\left(\mathrm{~K}^{-1 / 4}\right)$ for $\mathrm{Sr}_{3} \mathrm{NbCrO}_{7}$

\section{Results and Discussion}

\subsection{Crystal Structure}

The unit cell structural parameters of the phase were calculated from the X-ray diffraction data (Table 1). The indexing of the data shows that it crystallises in the tetragonal unit cell with $\underline{a}=3.994$ and $\underline{c}=21.015 \AA$. In order to determine the crystal structure, the theoretical X-ray diffraction data were generated by the Lazy-Pulverix analysis (Yvon, 1977). The structural parameters (positional co-ordinates, occupation factors and the space group I4/mmm) of the RP-type phase $\mathrm{Sr}_{3} \mathrm{Ti}_{2} \mathrm{O}_{7}$ (Ruddlesden \& Popper, 1958; Sharma, 2005) were the basis of 
the structural analysis. The positional co-ordinates and the occupancy factors applicable for $\mathrm{Sr}_{3} \mathrm{Ti}_{2} \mathrm{O}_{7}$ were gradually varied to arrive at the best fit theoretical d-values and their intensities matching the experimental data. The theoretical X-ray diffraction data are given along with the corresponding experimental data in the Table 1. Comparison of the two sets of the values shows that except for a line at the d-value $3.043 \AA$, which is attributed to some impurity, there is good agreement between the experimental and the theoretical data. This is especially true when no preferential orientation factors have been taken in to consideration. The agreement shows that the newly synthesised phase has crystallised in the RP-type $(\mathrm{n}=2)$ structure with the composition $\mathrm{Sr}_{3} \mathrm{NbCrO}_{7}$. The composition of the phase as $\mathrm{Sr}_{3} \mathrm{NbCrO}_{7}$ is based on the chemical structure $\left(\mathrm{Sr}^{2+}\right)_{3}\left(\mathrm{Nb}^{5+}\right)\left(\mathrm{Cr}^{3+}\right)\left(\mathrm{O}^{2-}\right)_{7}$. The occupancy factors for oxygen, $\mathrm{O}_{1}, \mathrm{O}_{2}$ and $\mathrm{O}_{3}$, (Table 2) which suggest the stoichiometry of oxygen as 7 , also substantiate this composition of the phase. Using the positional co-ordinates given in the Table 2 and the space group $\mathrm{I} / \mathrm{mmm}$, the cell structure has been drawn with the programme 'Powder' and the same is given in the Figure 3.

Table 1. Powder X-ray diffraction data of $\mathrm{Sr}_{3} \mathrm{NbCrO}_{7}$

\begin{tabular}{ccccccc}
\hline $\mathrm{h}$ & $\mathrm{K}$ & $\mathrm{l}$ & $\mathrm{d}_{\text {obs }}(\AA)$ & $\mathrm{d}_{\text {cal }}(\AA)$ & $\mathrm{I}_{\text {obs }}$ & $\mathrm{I}_{\text {cal }}$ \\
\hline 0 & 0 & 4 & 5.554 & 5.254 & 8 & 2 \\
1 & 0 & 3 & 3.106 & 3.469 & 35 & 10 \\
-- & -- & -- & 3.043 & ----- & 35 & -- \\
1 & 0 & 5 & 2.895 & 2.895 & 100 & 100 \\
1 & 1 & 0 & 2.824 & 2.824 & 76 & 76 \\
1 & 1 & 6 & 2.188 & 2.198 & 7 & 13 \\
0 & 0 & 10 & 2.077 & 2.102 & 20 & 10 \\
2 & 0 & 0 & 2.045 & 1.997 & 49 & 47 \\
2 & 0 & 2 & 1.959 & 1.962 & 7 & 2 \\
1 & 1 & 8 & 1.801 & 1.924 & 5 & 38 \\
1 & 1 & 10 & 1.673 & 1.686 & 41 & 38 \\
2 & 1 & 5 & 1.668 & 1.644 & 6 & 8 \\
2 & 0 & 8 & 1.606 & 1.590 & 6 & 6 \\
2 & 1 & 7 & 1.542 & 1.535 & 11 & 11 \\
2 & 0 & 10 & 1.441 & 1.447 & 8 & 13 \\
2 & 2 & 0 & 1.413 & 1.412 & 6 & 2 \\
2 & 2 & 2 & 1.381 & 1.399 & & 6
\end{tabular}

Space group: I4/mmm

$\mathrm{a}=3.994 \AA ; \mathrm{c}=21.015 \AA$

Table 2. Positional coordinates for $\mathrm{Sr}_{3} \mathrm{NbCrO}_{7}$

\begin{tabular}{llllc}
\hline Atom & $\mathrm{x}$ & $\mathrm{y}$ & $\mathrm{z}$ & Occupancy \\
\hline $\mathrm{Sr}(1)$ & 0.0 & 0.0 & 0.5 & 1 \\
$\mathrm{Sr}(2)$ & 0.0 & 0.0 & 0.3105 & 1 \\
$\mathrm{Nb} / \mathrm{Cr}$ & 0.0 & 0.0 & 0.075 & 1 \\
$\mathrm{O}(1)$ & 0.0 & 0.5 & 0.093 & 1 \\
$\mathrm{O}(2)$ & 0.0 & 0.0 & 0.1842 & 1 \\
$\mathrm{O}(3)$ & 0.0 & 0.0 & 0.0 & 1 \\
\hline
\end{tabular}




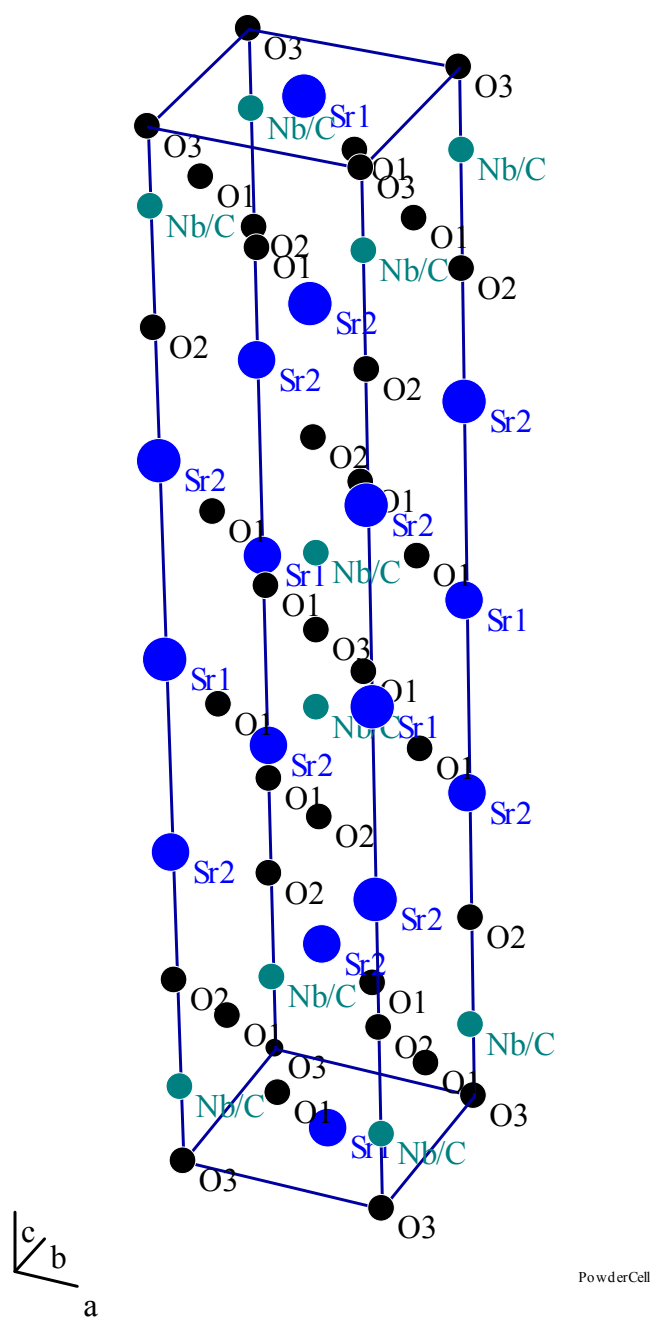

Figure 3. Unit Cell structure of $\mathrm{Sr}_{3} \mathrm{NbCrO}_{7}$

\subsection{Electric Transport Properties}

The $\log$ of specific resistance $(\log \rho)$ versus temperature $(\mathbf{K})$ values are plotted in the Figure 2 . The negative temperature co-efficient of resistivity and the values of the specific resistance show that the phase is semiconductor in nature. The plot of $\log \rho$ versus $\mathrm{T}^{-1 / 4}$ (Figure 2, inset) is linear, except at very low temperatures, which suggests that 3D hopping mechanism governs the electronic conduction in this phase (Helmolt, 1993; Sharma, 1999). The phenomenon is attributed to superexchange coupling of electrons. There is deviation from this mechanism at temperatures below $100 \mathrm{~K}$, indicating that the conditions of 3D hopping do not operate in this temperature region.

\section{Conclusions}

A new phase with the composition $\mathrm{Sr}_{3} \mathrm{NbCrO}_{7}$ has been synthesised by the standard ceramic method. On the basis of Lazy-Pulverix analysis of the X-ray diffraction data it is concluded that the phase crystallises in the RP-type $(\mathrm{n}=2)$ structure with $\mathrm{I} 4 / \mathrm{mmm}$ space group. The unit cell structure has been drawn. The study of electrical resistivity in the temperature range 10-300 $\mathrm{K}$ suggests that the compound is an electrical semiconductor and conduction above $100 \mathrm{~K}$ occurs through $3 \mathrm{D}$ hopping.

\section{Acknowledgements}

Thanks are due to the DST, New Delhi, for the financial support. 


\section{References}

Battle, P. D., Burley, J. C., Gallon, D. J., \& Grey, C. P. (2004). Magnetism and Structural Chemistry of the $\mathrm{n}=2$ Ruddlesden-Popper Phase $\mathrm{La}_{3} \mathrm{LiMnO}_{7}$. J. Solid State Chem., 177, 119-125. http://dx.doi.org/10.1016/S0022-4596(03)00333-5

Gupta, S., Singh, V., Sharma, B. L., \& Sharma, I. B. (2011). Structure, Electric Transport Properties of $\mathrm{LnSr}_{2} \mathrm{FeTiO}_{7} \quad(\mathrm{Ln}=\mathrm{La}, \quad \mathrm{Nd}$ and Gd). Bull. Mater. Sci., 34, 149-151. http://dx.doi.org/10.1007/s12034-011-0046-z

Helmolt, R. V., Wecker, J., Holzapfel, B., Schultz, L., \& Samwer, K. (1993). Giant Negative Magnetoristance in Perovskite Like $\mathrm{La}_{2 / 3} \mathrm{~B}_{1 / 3} \mathrm{MnO}_{\mathrm{x}}$ Ferromagnetic Films. Phys. Rev. Lett., 71, 2331-2333. http://dx.doi.org/10.1103/PhysRevLett.71.2331

Mahesh, R., Mahendiran, R., Raychaudhuri, A. K., \& Rao, C. N. R. (1996). Effect of Dimensionality on the Giant Magnetoresistance of the Manganates: A Study of the (La, Sr) $)_{n+1} \mathrm{Mn}_{\mathrm{n}} \mathrm{O}_{3 \mathrm{n}+1}$. J. Solid State Chem., 122, 448-450. http://dx.doi.org/10.1006/jssc.1996.0141

Matsukawa, M., Chiba, M., Kikuchi, E., Suryanarayanan, R., Apostu, M., Nimori, S., ... Kobayashi, N. (2005). Effect of Suppression of Local Distortion on the Magnetic, Electric and Thermal Transport Properties of the Cr-substituted Bilayer Manganite $\operatorname{LaSr}_{2} \mathrm{Mn}_{2} \mathrm{O}_{7} . \quad$ Phys. Rev. B, $72, \quad 224422$. http://dx.doi.org/10.1103/PhysRevB.72.224422

Ramirez, A. P., Cava, R. J., \& Krajewski, J. (1997). Colossal Magnetoresistance in Cr-based Chalcogenide Spinels. Nature, 386, 156159. http://dx.doi.org/10.1038/386156a0

Ruddlesden, S. N., \& Popper, P. (1958). The Compound $\mathrm{Sr}_{3} \mathrm{Ti}_{2} \mathrm{O}_{7}$ and its Structure. Acta Cryatallogr, 11, 54-55.

Sharma, I. B., Magotra, S. K., Singh, D., Batra, S., \& Mudher, K. D. S. (1999). Synthesis, Structure, Electric Transport and Magnetic Properties of $\mathrm{Sr}_{2} \mathrm{LaMn}_{1.5} \mathrm{Fe}_{0.5} \mathrm{O}_{7}$. J. Aloya and Comp., 291, 16-20. http://dx.doi.org/10.1016/S0925-8388(99)00257-1

Sharma, I. B., Kumari, S., \& Gupta, S. (2005). Synthesis, Structure, Electric Transport and Magnetic Properties of $\mathrm{Sr}_{3} \mathrm{Fe}_{2-\mathrm{x}} \mathrm{Nb}_{\mathrm{x}} \mathrm{O}_{7} \quad(\mathrm{x}=0.3, \quad 0.6, \quad$ and 1.0). J. Alloys and Comp., 402, 12-16. http://dx.doi.org/10.1016/j.jallcom.2005.04.179

Shilova, Y. A., Patrakeev, M. V., Mitberg, E. B., Leonidov, I. A., Kozhenikov, V. L., \& Poeppelmeier, K. R. (2002). Order-disorder Enhances Oxygen Conductivity and Electron Transport in Ruddlesden-Popper Ferrite-Titanate, $\mathrm{Sr}_{3} \mathrm{Fe}_{2-\mathrm{x}} \mathrm{Ti}_{\mathrm{x}} \mathrm{O}_{6+\mathrm{x}}$. J. Solid State Chem., 168, 275-283. http://dx.doi.org/10.1006/jssc.2002.9722

Shivakumar, T., Lofland, S. E., Ramanujachary, K. V., Ramesha, K, Subbana, G. N., \& Gopalakrishnan, J. (2004). Transforming $\mathrm{n}=1$ Members of the Ruddlesden-Popper Phases to a $\mathrm{N}=3$ member through Metathesis: Synthesis of a New Layered Perovskite, $\mathrm{Ca}_{2} \mathrm{La}_{2} \mathrm{CuTi}_{2} \mathrm{O}_{10}$. J. Solid State Chem., 177, 2635-2638. http://dx.doi.org/10.1016/j.jssc.2004.03.030

Tsipis, E. V., Patrakeev, M. V., Waerenborgh, J. C., Pivak, Y. V., Markov, A .A., Gaczynski, P., ... Kharton, V. V. (2007). Oxygen Non-stoichiometry of $\mathrm{Ln}_{4} \mathrm{Ni}_{2.7} \mathrm{Fe}_{0.3} \mathrm{O}_{10-\mathrm{x}}$. J. Solid State Chem., 180, 19012-1910. http://dx.doi.org/10.1016/j.jssc.2007.04.025

Yvon, K., Jeitschko, W., \& Parthe, E, (1977). Lazy Pulverix. Laboratorie De Crystallographic Aux Rayons-X, University De Geneve, Geneve, Switzerland. 